\title{
Apology Strategies of Iranian ESL Students
}

\author{
Haleh Parsa (Corresponding author) \\ Department of Languages and Linguistics \\ University of Malaya \\ Kuala Lumpur 50603, Malaysia \\ E-mail: parsa.haleh@gmail.com \\ Jariah Binti Mohd Jan \\ Department of Languages and Linguistics \\ University of Malaya \\ Kuala Lumpur 50603, Malaysia \\ Email: jariah@um.edu.my
}

Received: 17-07-2014

doi:10.7575/aiac.ijalel.v.4n.1p.137
Accepted: 04-09-2014

Published: 01-01-2015

\begin{abstract}
The main focus of this study, which is of the most important and most frequent speech acts used in multicultural settings, is the speech act of apology. It probes native Persian-speaking ESL university students' apology and nonapology strategies based on Cohen and Olshtain's (1981) frame work to evince variations ascribed to gender, mother tongue, and culture. The results of this survey reveal that Iranian male and female respondents use different percentages of apology and non-apology strategies. Considering significance levels, in general, except for a few strategies, there is no statistically significant difference between the groups considering the number and type of strategies used.
\end{abstract}

Keywords: ESL, Sociolinguistics, Politeness, Gender, mother tongue

\section{Introduction}

Every year, thousands of international students enrol in Malaysian universities. They come from various countries and represent a diverse range of cultures and languages. According to Shoja (2011), in the years 2007-2009, "2473 postgraduate international candidates enrolled in University of Malaya". Iranian students have been the largest group of international candidates to enrol in UM every year. This number for the years 2007-2009 is 695, which is more than $28 \%$ of the total number of postgraduate international candidates. Shoja (2011) reports that "the second largest group is Indonesians $(\mathrm{N}=296)$ which includes almost $12 \%$ of the international students. Candidates from Iraq, Sudan, China, Kingdom of Saudi Arabia, and Yemen stand next". Figure 1 shows the number of "postgraduate international students enrolled in UM from 2007 to 2009 from the countries with more than 20 candidates" (Shoja, 2011).

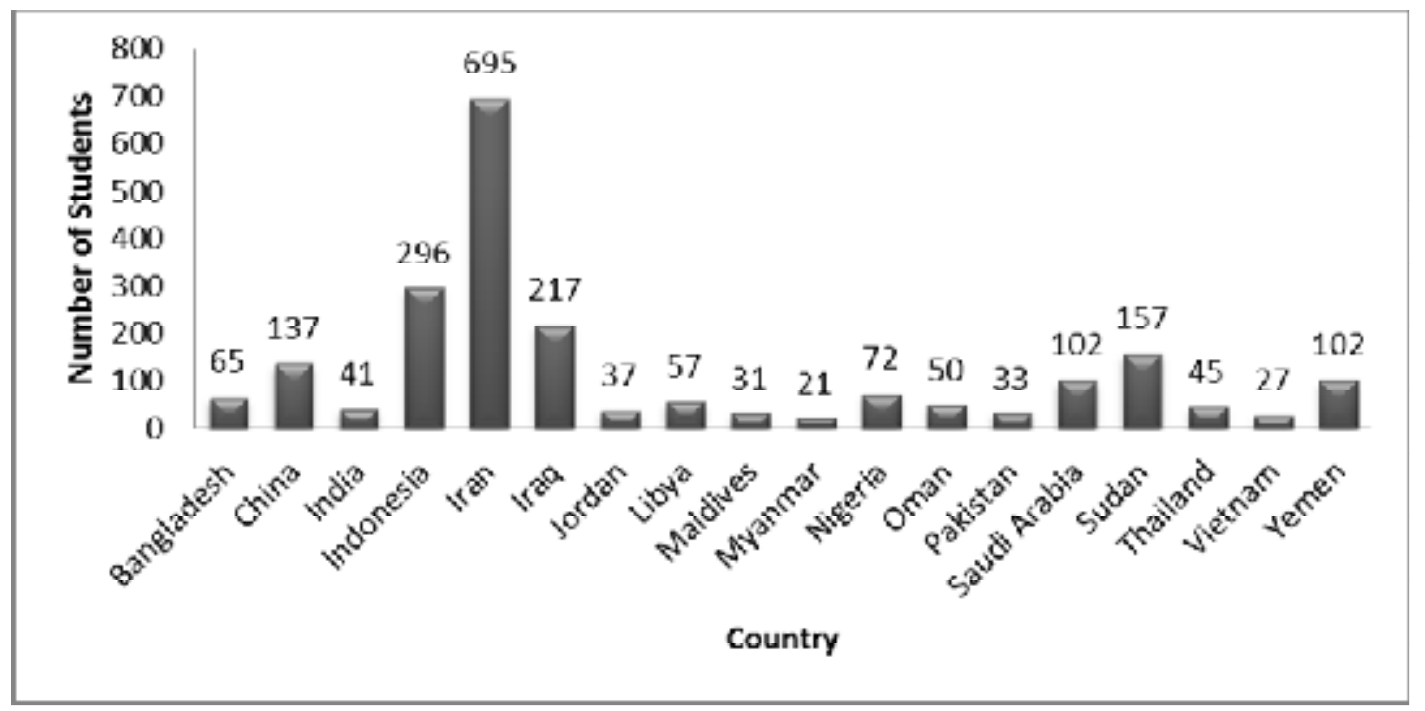

Figure 1. Postgraduate International Students Enrolled in 2007-2009 (Shoja, 2011)

Unlike in Iran, where English is not at all used in daily interaction, or in formal or official contexts, Iranian students who are living and studying in Malaysia are using and learning English as a second language. The English curriculum 
offered in Iranian schools is not communication-based. The methods of English teaching are widely grammar translation technique that contains extensive memorization, readings and translation activities. There is very little emphasis on spoken skills of English, and the assessment is largely based on written exams. According to Ghorbani (2009), "In Iran, the highly standardized national tests force both teachers and learners to focus only on structural or formal grammatical features of English because these are the ones needed to perform well in the exams". Dahmardeh (2008) asserted "the vast majority of language exams and tests in Iran fail to assess real communicative language content, teaching communicative skills becomes or remains a neglected component in many foreign language classrooms".

The speech act of apology is perceived as a complex interaction by Iranian students as misunderstandings resulting from assumptions and beliefs are more serious than linguistic incompetence in intercultural communications. Although politeness is a universal value, it is expressed in different ways across different cultures. Expressions, idioms, or even body language signals that might be polite and acceptable in a given society, might be considered rude or insulting in another. In addition, negative transfer of some socio-cultural norms of L1 into English may cause some misapprehensions and communication failures. According to numerous studies done, which will be reported in the following sections, nationality, mother tongue, and common cultural values influence the kind and variety of apology strategies used. Being unaware of these cultural and linguistic influences might cause miscommunication or misinterpretation in an international setting. According to Olshtain and Cohen (1981) formal instructions on the use of speech acts can accelerate the process of learning the target language.

Looking at the importance of inter-cultural awareness in achieving effective communication in a multi-cultural setting such as University of Malaya, one can argue that being aware of the Iranian culture and the ways it affects their use of apology strategies is of utmost importance. Since almost all the researches reviewed have been done in the EFL context of Iran, the present study aims to look at Iranian students' apology and non-apology strategies in an ESL setting (Malaysia). The results of this study could be beneficial for different stakeholders in relation to this field, namely, the Iranian students pursuing their tertiary education in English and outside Iran, university lecturers and staff who interact with Iranian students speaking English as a second or foreign language, and English language teachers who have Iranian students, and any researcher who is interested in this area of research.

\section{Review of literature}

\subsection{Interlanguage Pragmatics in Second Language Learning}

Recently, literature includes a lot of studies on inter language pragmatics that implies learners' ability in acquiring L2 pragmatics (Kasper \& Blum-Kulka, 1993; Kasper \& Rose, 1999; Rose, 2000). Bergman and Kasper (1993) believed that foreign language learners make use of positive transfer from their L1 into The foreign language, but it is not always possible because of pragmatic variations across cultures and languages. Blum-Kulka (1991) investigated American immigrants to Israel who were proficient in two languages. The results revealed that they used an intercultural style of speaking that was both similar and different from the common styles in those languages. Furthermore, this researcher asserted that adult learners receive a lot of L2 pragmatic knowledge. Some aspects of this pragmatic knowledge are universal but the others are transferred from L1. Conversational organization through turn taking and sequencing of contributions are considered as universal aspects of discourse and pragmatics.

Koike (1996) who investigated the perception of Spanish suggestions by English-speaking learners of Spanish showed that proficiency affects the recognition of the intent of speech acts, but Takahashi (1996) found no relationship between proficiency and perception of L1 transferability to L2 pragmatics. According to Ren (2013) longitudinal studies in ILP are limited and a significant area of research yet to be undertaken (Kasper and Rose, 2002).

\subsection{Politeness in Iranian Culture and Persian Language}

The term "politeness" indicates good manners and correct social behaviour (LogaMahesanBaskaran, 2005). We have to learn it because we are not born with it (Richard J. Watts, 2003). Baskaran (2005) argued that "Various factors influence the degree of politeness like social distance, degree of formality, the social power, and the cultural context." Lakoff (1973) defined three major rules of politeness such as "do not impose", "give options", "make the hearer feel good", and "be friendly". He believed that people perceive politeness differently due to various priorities that they give to specific rules.

Eslami (2005) looked at the structure of invitation in Persian and English. He used participant observation and semistructured interviews for collecting data. The findings indicated that Persians aimed to achieve ritual politeness in issuing and replying to invitations and a genuine invitation in English was perceived as an ambiguous invitation in Persian. Ta'arof, which is an intricate expression of five concepts, forms the Iranian system of politeness. These five notions, which imply courtesy, respect, self-restraint, modesty, and hospitality, have been pointed out by many researchers (Hodge, 1957; Beeman, 1976, 1986; Assadi, 1980; Rafiee, 1992; Koutelaki, 1997; Sahragard, 2000). Moosavi (1986) defined ta'arof as ritualized linguistic forms that appear in the interaction of Iranians. Sahragard (2000) asserted that courtesy (Adab) is a personal feature that is obtained based on good upbringing, but respect (Ehteram) is a sense of ethical obligation and a subjective matter. Iranians usually greet each other in a very friendly manner and prolong it to show respect. Children become familiar with the notion of respect at home and expand it to their friends and relatives. Self-restraint or being ashamed is another constituent notion of ta'arof in the Persian culture. According to Dehkhoda (1994) sharm and haya are two Persian synonyms for being ashamed. Jorjani (1994) stated that haya means to avoid doing or saying something that is socially or morally inappropriate. Furthermore, Persians often refuse to 
accept their abilities, traits, or assets to show their modesty. In other words, they lower their status by using selflowering strategies. They believe that people of higher status must be more humble like a fertile tree that bends its branches.

\subsection{Speech Act of Apology}

Speech acts are performed when speaker in a language intends to offer an apology, request, greeting, complaint, compliment, or refusal. In such situations, speech acts are utterances for communication with the interlocutor. A speech act can be formed of single word such as "Sorry!", or multiple words or sentences such as "it was my fault," or "I'm sorry I forgot your birthday. Austin (1975) and Searle (1969) were forefathers of speech act theory. They were influenced by Saussure (1959) who claimed the difference between "Language" and "Parole" and Chomsky's (1965) theory of competence and performance to define a theory of action. Austin (1975) emphasized on performative utterance in his book, How to Do Things with Words, because he believed that we perform actions by utterances. On the other hand, Searle (1969) claimed that "talking is performing acts according to rules".

Blum-Kulka et al (1993) also considered that "apology as a speech act intends to compensate for the offence or violation the speaker brings about which might end up with a friction between the speaker and the hearer." However, the apologizer who tends to verbally apologize for the violation needs to humiliate herlhimself to an extent which accords the type and impression of the offence accepting the responsibility for reconciliation. This way, an apology can serve the speaker as a face threatening act and for the victim as face saving act.

\subsection{Categorization of Apology Strategies}

Before introducing different categorization of apology strategies, it seems necessary to define some of the main terms. The following definitions are reported as cited by Bataineh and Bataineh (2008).

- Accounts are the strategies in which the wrongdoer states the reason of the violation/offence such as traffic was heavy.

- Taking on responsibility in which the offender takes responsibility for his/her violation like it was my mistake.

- Lack of intent in which the offender tries to assure the victim that what happened was not on purpose.

- $\quad$ Gratitude in which the wrongdoer appreciates the victim for the time to speak

- $\quad$ Self-castigation in which the wrongdoer criticizes her/his behaviour.

- Contextualization in which the transgressor tries to show the entire context to the hearer.

- $\quad$ Reparation in which the offender tries to fix the harm or offer words to help the victim forget it.

- $\quad$ Compensation in which the wrongdoer wants to recompense for the damage

- Promise of forbearance in which the offender assures the hearer that the violation will not happen again Based on Fraser (1981) apology strategies are classified into six categories.

(1) Announcing that you are apologizing

(2) Stating one's obligation to apologize

(3) Offering to apologize

(4) Requesting that the hearer accept an apology

(5) Expression of regret

(6) Requesting forgiveness for the offence

Similar to Fraser's classification, Trosborg (1987) suggested the wrongdoer to use the following apology strategies.

(1) Accusing someone else or debate to reduce the level of the violation.

(2) Using the following six types based on the extent that the wrongdoer admits his/her fault:

- Implicit acknowledgement

- Explicit acknowledgement

- Showing lack of intention

- Indicating self-deficiency

- $\quad$ Showing embarrassment

- $\quad$ Accepting the fault explicitly

(1) Accounts

(2) Reparation is performed in two ways:

- Defray for doing damage

- $\quad$ Recompense to balance the offence

(1) Promise of avoidance

(2) Showing apprehension for the victim 
Blum-kulka, House and Kasper (1989) suggested the following apology strategies:

- $\quad$ IFIDs in which the wrongdoer apologizes explicitly, e.g. 'I am sorry'.

- $\quad$ Taking responsibility in which the speaker takes responsibility for the offence.

- $\quad$ Promise of forbearance when the speaker promises that the violation wiil not happen again in future

- $\quad$ Showing embarrassment, e.g. 'I'm ashamed'.

- $\quad$ Account is used to express reasons, e.g. 'Traffic was heavy'.

- Reparation in which the wrongdoer wants to fix the damage or offers words to help the victim forget the harm, e.g. 'I will make it up to you'.

- Distracting from the offence that includes two types of strategies such as query precondition and future remark, e.g. 'let's go to the party then...'

Cohen and Olshtain (1981) classified the following apology strategies:

- $\quad$ IFID (Illocutionary Force Indicating Device) like sorry, excuse me, and I apologize.

- $\quad$ Taking on responsibility for the offence such as it was my fault.

- Account to show the cause of the offence such as traffic was heavy.

- $\quad$ An offer of repair such as I will fix it.

- A promise of forbearance such as I will not do it again.

\subsection{Apology and Politeness}

Brown and Levinson (1978) argued that "politeness strategies intend mainly to save the addressees' face". They presented the concept of face in their model of politeness theory as a self-image and defined face threatening speech acts according to some parameters like the speaker, the hearer, and the type of face. Based on their politeness theory, positive face which is a tendency to be liked by others is kept safe with a friendly behaviour (positive politeness), while a negative face is protected by a manner that avoids impeding (negative politeness). Therefore, people use positive and negative politeness strategies to decrease the face-threat. So far, numerous researchers have discussed this theory in their intercultural studies (Gu, 1990; Mao, 1994; Matsumoto, 1988; Bargiela-Chiappini, 2003; watts, 2003).

Holmes (1990, p. 156) believes that the speech act of apology is interrelated to politeness and its objective as a social act is to save positive relations between speaker and hearer. Apology is a sign and act of politeness from speaker's side which demonstrates her/his concern about such a relation and its maintenance between her/himself and the victim. The following section will discuss the relationship between the acts of apology and politeness which is intended to reconcile the two parties, i.e., the offender and the victim.

\subsection{Apology and Culture}

Based on Gries and Peng (2002), there is a great difference in causal reasoning and responsibility assessment between East and West. For instance, a Chinese may concentrate on the result of the happening, but an American try to find the wrongdoer in a special circumstance. In Chinese culture, people are usually ready to apologize because they believe that it solves problems and wipes off many of sins. Al-Zumore (2003, p. 29) argued that in Arab culture, "admitting one's deficiency to set the things right is not as embarrassing as in the Anglo-Saxon culture". People are more available to each other and more careless about their immunity.

Bataine (2008) investigated common apology strategies used by Americans and Arabs. Participants were all undergraduate students ranged between 17 and 24. It was conducted according to Lipson's (1994) framework. The results showed that both groups used distinct apology strategies. All of them employed explicit strategies and combined two or more apology strategies to reveal regret. Furthermore, manifestations were mostly applied by Jordanians.

IlkinIstifci (2009) examined two different levels of English proficiency to find out differences and similarities in using apology strategies between them and whether they use native speaker apology norms or not. It was based on Cohen and Olshtain's (1981) and 20 intermediate level students, 20 advanced level students and 5 native speakers were the participants of this study. The researcher reported that there were some similarities and differences between the two groups. There was an influence of L1 on their use of apologies and native Turkish speaker norms mostly transferred by intermediate levels into English. Furthermore, advanced level subjects used more native speaker norms unlike their intermediate counterparts.

\subsection{Apology and Gender}

Researchers began to consider gender variations in employing the speech act of apology in 1970s and their studies revealed critical facts about men and women. Bataineh and Bataineh (2006) investigated EFL students' use of apology in Ibrid. The findings indicated that although males and females used some similar strategies, they applied them in various orders. Furthermore, female respondents tried to avoid debating the violation, but males attempted to accuse the victim. Abu Amoud (2008) analyzed the apology and non-apology strategies of Palestinian students in Hebron University based on Cohen and Olshtain's (1981) framework. The results revealed that females employed more apology strategies compared to male participants due to their shyness and politeness attributes. On the other hand, males used further non-apology strategies because of male predominated society of Palestinians. Also, women talked more to attain the victim's forgiveness, but men preferred few words and ignored the consequence. 
Bataine and Bataine (2008) studied apology strategies used by American and Arab EFL university students. The results showed that although both groups used two expressions of apology and two intensifiers, females expressed the apologies more overtly. In addition, females employed more reparation, promise of forbearance, self castigation, recompense, and less non- apology strategies in comparison with American male respondents. On the other hand, all participants used prime apology speech acts in various order. Males used accounts, reparation, compensation, showing lack of intent, and promise of forbearance, while females used accounts, promise of forbearance, reparation, compensation, and lack of intent. Unlike males, Jordanian females apologized more, especially to males and blamed themselves for their faults instead of attacking the victim to show their readiness to make them up.

\subsection{Apology in Persian}

In the Persian culture, people's feelings, face, and belongings are fully respected because all human beings are considered as different parts of the same body. According to Shariati and Chamani (2009), "apologies in Persian are formulaic and really culture specific" ( p: 9). Although Persian speakers use the same apology strategies, IFID with a request for forgiveness is used more than the others. Moreover, a combination of IFID with taking on responsibility is used in all situations". Eslami-Rasekh and Mardani (2010) investigated the effectiveness of direct instructing of apology strategies. The results revealed the usefulness of this teaching. Students' lack of sociopragmatics proficiency forced them to use more intensifiers. The aim of their study was to give teachers and learners awareness of socio-cultural and sociolinguistic differences to realize the reason of failure in communication. They believed that Persian L2 learners should be exposed to the usual apology strategies used by native speakers to refuse negative transfer "excuse me" of Persian apology. From their point of view, it is essential for material developers, and teachers to give more importance to apology speech act.

Farashaiyan and Yazdi Amirkhiz (2011) investigated the apology strategies used by Iranian EFL and Malaysian ESL students. The researcher used a Discourse completion test (DCT) to collect data. The sample of the study included 15 Iranian and 15 Malaysian students. The results indicated Iranian and Malaysian learners used some different and similar apology strategies. Iranians used fifteen apology strategies out of seventeen strategies, while Malaysians used eleven types of apology strategies. This review of literature shows that nearly all the studies have been in EFL contexts unlike the current study which examines apology and non-apology strategies of Iranian students in an ESL setting and there are a few studies scrutinizing the use of apology and non-apology strategies by Persian postgraduate ESL students, this study addresses the research gap in the field of apology strategies and aims to answer the following research questions:

(1) What are the apology strategies used by Iranian ESL students?

(2) What kinds of non-apology strategies do Iranian ESL students use most often?

(3) To what extent are the Iranian respondents' strategy use related to gender?

(4) What are the apology and non-apology strategies used by the Iranian ESL students that are influenced by Iranian culture and the Persian language?

\section{Methodology}

\subsection{The sample}

The participants of the study consisted of one selected group of 40 Iranian postgraduate ESL students (20 males, 20 females) ranged between 24-35 from the Faculty of Languages and Linguistics and the Faculty of Education at University of Malaya. The respondents were nearly homogeneous in their cultural background and academic/linguistic experiences.

\subsection{The data collection procedures}

The data collection started in April 2010 and lasted for one month. As there were some difficulties in accessing all number of participants, the researcher e-mailed the open-ended questionnaire to them. Except for some respondents who filled it out directly at the main library, the others sent it back via e-mail. The students were supposed to read the situations consider themselves in the situations and write down their normal reactions. The open questionnaire was in English and the respondents were asked to write their answers in English.

\subsection{The Analysis of Data}

Responses to the open questionnaire were coded and fed to the computer using the SPSS package. Descriptive statistics with one-way frequency distribution was used and the results were defined as frequency counts and percentages. The researcher identified and tabulated all apology strategies used by respondents based on Cohen and Olshtain's (1981) framework, which was also used in CCSARP project by Blum-Kulka et al., (1982). The significant values were calculated to identify and analyze the differences attributed to gender, encompassing non-apology strategies. In this study, the researcher will use Cohen and Olshtain's strategies as the basis of her data analysis, although the other classifications will be considered in mind. Cohen and Olshtain (1981), who introduced the notion of 'the speech act set of apology', identified the following apology strategies: 
- A request for forgiveness, e.g. excuse me/ forgive me/ pardon me.

(2) Explanation or account, e.g. there was a heavy traffic.

(3) Taking on responsibility:

- $\quad$ Explicit self-blame, e.g. it's my mistake.

- Lack of intent, e.g. I didn't do it on purpose.

- $\quad$ Expression of self-deficiency, e.g. I totally forgot it.

- $\quad$ Expression of embarrassment, e.g. I feel ashamed.

- $\quad$ Self-castigation, e.g. It was very stupid of me.

- Justify the hearer, e.g. you are right to be angry and disappointed now.

(4) An offer of repair, e.g. I'll pay for the damage.

(5) Promise of forbearance, e.g. it won't happen again.

\section{Findings and Discussion}

The findings obtained from the DCT suggest answers to the four research questions.

\subsection{Analysis of Research Question 1}

The first research question of the study is: what are the apology strategies used by Iranian ESL students?

\subsubsection{IFID}

One expression of regret; In $28.0 \%$ of the situations $(n=56)$, male respondents used one expression of regret like sorry, while in $39.5 \%$ of the situations $(n=79)$, female respondents used it in response to all questionnaire items to express regret.

One expression of regret and one intensifier; In $29.0 \%$ of the situations $(n=58)$, male respondents used one expression of regret and one intensifier such as really sorry, terribly sorry and too sorry. In $42.5 \%$ of the situations $(n=85)$, female respondents used one expression of regret and one intensifier like so sorry, really sorry and terribly sorry in response to all questionnaire situations to show regret.

One expression of regret and two intensifiers; In only $0.5 \%$ of the situations $(n=1)$, male respondents used "one expression of regret and two intensifiers" such as "really so sorry" just in response to item 1 to show regret for the violation. On the other hand, in $3.5 \%$ of the situations $(n=7)$, female respondents used "one expression of regret and two intensifiers" such as "very very sorry" and "so so sorry" just in response to items 1, 4, 5, 7, and 9 to express regret for the violation.

One expression of regret and three intensifiers; In only one instance $(0.5 \%)$, a female respondent used "one expression of regret and three intensifiers" saying "so so so sorry" in response to item 1 to express regret for the offence. It is worth noting that "one expression of regret and three intensifiers" was not used by any Iranian male respondent.

An offer of apology; In 19.0\% of the situations ( $\mathrm{n}=38)$, male respondents used "an offer of apology", for example, "I do apologize" to show sorrow; while Iranian respondents used an offer of apology such as "please accept my apologies", "I apologize", and "I do apologize" in $7.5 \%$ of the situations $(n=15)$ in response to all items except items 5 , 6 , and 10 to show their sorrow.

A request for forgiveness; In $8.0 \%$ of the situations $(n=16)$, male respondents used a request for forgiveness, for instance, "excuse me", "forgive me" and "pardon me" in response to all questionnaire items except item 8 to show regret for the offence. Female respondents, on the other hand, used "a request for forgiveness" such as "please forgive me", "excuse me", and "please pardon me" in $12.5 \%$ of the situations $(\mathrm{n}=25)$, in response to all questionnaire.

\subsubsection{Apology Strategies Based on Cohen and Olshtain's (1981) Categorization}

Accounts; In $39.0 \%$ of the situations $(n=78)$, male respondents used accounts in response to all items except 3,7 , and 9. Two examples are shown below:

I was horribly sick [2].

On the other hand, in $35.0 \%$ of the situations $(\mathrm{n}=70)$, female respondents used accounts in response to all items except 3 , and 9 , as shown below:

There was a heavy traffic [4].

Expression of self-deficiency; In $10.5 \%$ of the situations $(n=21)$, male respondents used expression of self-deficiency in their responses to items 4, 5, 9, and 10. Two examples are given below:

Oh, I forgot it [5].

While, female respondents used expression of self-deficiency in response in $14.0 \%$ of the situations $(n=28)$, to all items except 1,2,8, and 9, which resulted in answers such as:

I totally forgot about it [5].

Self-castigation; Male respondents used self-castigation in $8.0 \%$ of the situations $(n=16)$ in response to all items but 2 and 4. Examples are: 
It was very stupid of me [6].

Female respondents used self-castigation in only $3.5 \%$ of the situations $(n=7)$ in response to items $1,4,6,8$, and 9 . Responses came as follows:

I had to be more cautious [9].

Expression of embarrassment; In only $3.5 \%$ of the situations $(n=7)$, male resndents expressed their embarrassment in response to all items except 2, 5, 6, 7, and 9. Examples are:

I'm ashamed for such a long delay Sir [4].

On the other hand, in $6.5 \%$ of the situations $(\mathrm{n}=13)$, female respondents used this especially in their responses to items $1,2,5,6,7$, and 9 as is shown below:

It's really embarrassing [7].

Lack of intent; In $3.0 \%$ of the situations $(n=6)$, male respondents rejected intending to hurt the victim in response to items 1,3 , and 7. Examples of the use of this strategy are:

I didn't mean it [7].

In $4.0 \%$ of the situations $(n=8)$, Iranian female respondents rejected intending to hurt the victim in response to items 1 , 3,7 , and 9. Examples of the use of this strategy are:

I did not do it on purpose [7].

Promise of forbearance; Iranian male respondents promised not to repeat the offence in the future in $3.0 \%$ of the situations $(\mathrm{n}=6)$ in response to items 6 and 8 . Responses appeared as follows:

I promise it won't happen again [6].

In $4.0 \%$ of the situations $(n=8)$, female respondents promised not to repeat the offence in future, in response to items 4 , 5,6 , and 8. Examples are:

I promise not to do it again [5].

Explicit self-blame; In $1.5 \%$ of the situations $(\mathrm{n}=3)$, male respondents accepted their fault. This was clear in responses to items 2,3 , and 8 as is shown below:

It was my fault [8].

At the same time, in $5.0 \%$ of the situations $(\mathrm{n}=10)$, female respondents accepted their fault. This was clear in responses to items $1,4,6,8$, and 9 as is shown below:

It's my fault [8].

Justify the hearer; In $1.5 \%$ of the situations $(\mathrm{n}=3)$, female respondents used justified the hearer in response to item 4,5 , and 6 as shown in the following examples:

I know you are right to be angry [5].

On the other hand, in $0.5 \%$ of the situations $(n=1)$, Iranian male respondents used this strategy in response to item 6 . Example of the use of this strategy is:

I know how upset you are [6].

Reparation; In $8.5 \%$ of the situations $(n=17)$, male respondents used reparation in response to all items except $2,3,4$, 8 , and 9 as is shown below:

I want to make it up by buying something for you [6].

At the same time, in $11.5 \%(n=23)$ of the situations, female respondents offered words to help the victim forget the harm in response to all items except items 3 , and 4 . Responses came as follows:

Let's go and have a drink first to make it up to you [6].

\subsubsection{Apology Strategies Based on the Researcher's Categorization}

Compensation; In $13.0 \%$ of the situations $(n=26)$, male respondents used compensation in response to all items except $3,4,6$, and 8 . Examples of the use of this strategy are:

I go back to the bookstore to get it my dear [10].

While, in $9.5 \%$ of the situations ( $\mathrm{n}=19)$, female respondents used compensation in response to items $1,5,7$, and 10 as is shown below:

I will clean it now [7].

Referral compensation or reparation; In $12.0 \%$ of the situations $(n=24)$, male respondents used referral compensation or reparation which resulted in answers such as

Can I buy it tomorrow on my way back home [10]?

On the other hand, female respondents used referral compensation or reparation in $15.5 \%$ of the situations $(\mathrm{n}=31)$, in response to all items except 3,6, 7, and 8. Examples of the use of this strategy are: 
I'll rewrite them for you if you want [1].

Promise of better time; male respondents promised the victim better times particularly in $10.0 \%(\mathrm{n}=20)$ of the instances, in response to items 2,5 , and 10 . Responses came as follows:

Let's go to the cinema another day [5].

Female respondents promised the victim better time in $9.0 \%$ of the situations $(n=18)$ in response to items $2,4,5$, and 10.Examples are:

I'll buy it tomorrow [10].

Concern for the victim; this strategy appeared in $6.5 \%$ of the situations $(n=13)$ especially in male's responses to items $2,3,9$, and 10 as is shown below:

Are you ok [3]?

In $12.5 \%$ of the situations $(\mathrm{n}=25)$, female respondents used concern for the victim in responses to all items except 2,5 , and 10 as is shown below:

Are you ok [9]?

Cursing the cause of the violation; In 3.0\% of the situations $(n=6)$, male respondents cursed the cause of the violation to express their regret in response to items 3 , and 10 as shown in the following examples;

Oh, damn it [10]!

It is worth noting that this strategy was not used by any female respondent.

Expression of love; In $2.0 \%$ of the situations $(n=4)$, male respondents expressed their love in response to items 5 , and 6 as is shown below:

I love you [6].

While, in only $1.0 \%$ of the situations $(\mathrm{n}=2)$, female respondents used this strategy in response to Items 5 , and 6 as is shown below:

I love you babe [5]

Gratitude; In $1.5 \%$ of the situations ( $(n=3)$, Iranian male respondents used gratitude in response to item 6 as is shown in the following examples:

It's really sweet of you [6].

On the other hand, in $0.5 \%$ of the situations $(\mathrm{n}=1)$, female respondents used gratitude in response to item 1 as is shown in the following example:

I would like to appreciate you for what you have done to me, thanks a lot [1].

Asking victim not to be angry or worry; In only $1.0 \%$ of the situations

$(n=1)$, male respondents asked victim not to be worry or angry in response to items 1 and 10. Examples of the use of this strategy are:

Don't worry about it [1].

Female respondents did not use this strategy in response to any of the items.

Using idioms; In $0.5 \%$ situations $(\mathrm{n}=1)$, Iranian male respondents used this strategy in response to Item 6 as is shown in the following example:

I'm down in the mouth buddy for being late [6].

Female respondents did not use this strategy at all.

Invoking Allah's name; In 1.3\% of the situations ( $\mathrm{n}=5$ ), female respondents mentioned Allah's (God's) name to show that everything is by the hand of Allah and his will, in response to items 1, 4, 5, and 6 as shown in the following examples;

We will go there tomorrow "Insha'Allah" [5].

This strategy was not used by any Iranian male respondent.

Overall, "one expression of regret and one intensifier" and "one expression of regret" has been the most frequently used IFIDs by Iranian male and female respondents, in 35.8 and $33.8 \%$ percent of the instance respectively. Beside, one expression of regret and two or three intensifiers seem to be the least frequently used strategies, being used only in $2.0 \%$ and $3 \%$ of the instances. On the other hand, the most frequently used apology strategies by both male and female respondents are "accounts", "referral compensation/ reparation", "expression of self-deficiency", "compensation", and reparation. "Using idioms", "asking victim not to be angry or worry", "justify the hearer", and "gratitude" have been the least frequently used strategies. It is worth noting that strategies like "asking victim not to be angry or worry", "using idioms", and "cursing the cause of the violation" were not applied by any of the female respondents.

\subsection{Analysis of Research Question 2}

The second research question of the study is: what kinds of non-apology strategies do Iranian ESL students use most 


\section{often?}

\subsubsection{Non-apology Strategies}

Denial of responsibility; In $1.5 \%$ of the situations $(n=3)$, male respondents did not take responsibility for the offence in response to items 1,2 , and 3 as shown in the following examples;

It wasn't my fault [1].

On the other hand, in $9.5 \%$ of the situations $(n=19)$, female respondents did not take responsibility for the offence in response to all items except 4, 5, 7, and 9 as shown in the following examples;

It wasn't my fault [1].

Avoidance of subject or person; In $1.0 \%$ of the situations $(n=2)$, male respondents attempted to avoid discussing the offence.

Blaming the victim; In $0.5 \%$ of the situations $(n=1)$, male respondents blamed the victim for the violation in response to item 9 as shown in the following example:

Watch out [9]!

While, in $1.5 \%$ of the situations $(n=3)$, female respondents blamed the victim for the violation in response to item 5 as shown in the following example:

You should have reminded me [5].

Laughing the incident off; In only one situation a male respondent used laughing the incident off as a non-apology strategy. This was obvious in response to item 1. Example is:

Hehehe [1].

Brushing off the incident as not important; only one of the male respondents tried to persuade the victim that the offence is not very important as is shown in response to item 1. Example of the use of this strategy is:

Take it easy [1].

Similarly, only one of the female respondents tried to persuade the victim that the offence is not very important as is shown in response to item 10. Example of the use of this strategy is:

One day makes no difference [10].

Overall, "denial of responsibility" has been most frequently applied by male and female respondents. "Laughing the incident off" and "brushing off the incident as unimportant" have been rarely used. This very little use of these strategies shows that Iranian male and female participants do not tend to pretend the offence as unimportant, and try to use other apology or even no-apology strategies to deal with the situations. Moreover, offending the victim was not used by any Iranian male or female respondent. In the end, it should be noted that laughing the incident off, avoidance of subject or person, and offending the victim were not used by any female respondent.

\subsection{Analysis of Research Question3}

The third research question asks: to what extent are the Iranian respondents' strategy use related to gender?

\subsubsection{Differences in Use of Apology Strategies Based on Gender}

\subsubsection{IFID}

As is shown in table1, Iranian male and female respondents were unlike in using explicit expressions of apology.

Table 1. Statistical Comparison of Male and Female Respondents in Using IFDI

\begin{tabular}{lcccccccc}
\hline \multirow{2}{*}{} & \multirow{2}{*}{ IFID } & \multicolumn{2}{c}{ Male } & \multicolumn{2}{c}{ Female } & \multicolumn{3}{c}{ Total } \\
\cline { 2 - 8 } & & $\mathrm{N}$ & $\%$ & $\mathrm{~N}$ & $\%$ & $\mathrm{~N}$ & $\%$ & \\
\hline 1 & One expression of regret & 56 & 28.0 & 79 & 39.5 & 135 & 33.8 & 0.015 \\
\hline 2 & One expression of regret \& 1 intensifier & 58 & 29.0 & 85 & 42.5 & 143 & 35.8 & 0.005 \\
\hline 3 & One expression of regret and two intensifiers & 1 & 0.5 & 7 & 3.5 & 8 & 2.0 & 0.032 \\
\hline 4 & One expression of regret and three intensifiers & 0 & 0 & 1 & 0.5 & 1 & 0.3 & 0.317 \\
\hline 5 & An offer of apology & 38 & 19.0 & 15 & 7.5 & 53 & 13.3 & 0.001 \\
\hline 6 & A request for forgiveness & 16 & 8.0 & 25 & 12.5 & 41 & 10.3 & 0.138 \\
\hline
\end{tabular}

The IFID strategies used by these respondents were significantly different in four out of six cases. 
4.3.2 Apology Strategies based on Cohen and Olshtain's (1981) Categorization

Table 2 displays the statistical comparison of male and female respondents in using apology strategies based on Cohen and Olshtain's (1981) categorization.

As shown in the Table 2, male and female respondents were not significantly different in using the apology strategies suggested by Cohen and Olshtain's (1981), as in only one out of nine strategies, the P value is less than 0.05.

Table 2. Statistical Comparison of Male and Female Respondents in Using Apology Strategies: Cohen and Olshtain's (1981) Categorization

Table 2. Statistical Comparison of Male and Female Respondents in Using Apology Strategies:

Cohen and Olshtain's (1981) Categorization

\begin{tabular}{lcccccccc}
\hline \multirow{2}{*}{ Strategies } & \multicolumn{2}{c}{ Male } & \multicolumn{2}{c}{ Female } & \multicolumn{2}{c}{ Total } & \multirow{2}{*}{$P$ value } \\
\cline { 2 - 8 } & $\mathrm{N}$ & $\%$ & $\mathrm{~N}$ & $\%$ & $\mathrm{~N}$ & $\%$ & \\
\hline 1 & Accounts & 78 & 39.0 & 70 & 35.0 & 148 & 37.0 & 0.407 \\
\hline 2 & Expression of self-deficiency & 21 & 10.5 & 28 & 14.0 & 49 & 12.3 & 0.286 \\
\hline 3 & Self-castigation & 16 & 8.0 & 7 & 3.5 & 23 & 5.8 & 0.053 \\
\hline 4 & Expression of embarrassment & 7 & 3.5 & 13 & 6.5 & 20 & 5.0 & 0.169 \\
\hline 5 & Lack of intent & 6 & 3.0 & 8 & 4.0 & 14 & 3.5 & 0.586 \\
\hline 6 & Promise of forbearance & 6 & 3.0 & 8 & & 14 & 3.5 & 0.586 \\
\hline 7 & Explicit self-blame & 3 & 1.5 & 10 & 5.0 & 4.0 & 3.3 & 0.048 \\
\hline 8 & Justify the hearer & 1 & 0.5 & 3 & 1.5 & 4 & 1.0 & 0.315 \\
\hline 9 & Reparation & 17 & 8.5 & 23 & 11.5 & 40 & 10.0 & 0.317 \\
\hline
\end{tabular}

\subsubsection{Apology Strategies based on the Researcher's Categorization}

The Table 3 shows that except for three out of 10 strategies, there is no statistically significant difference between the groups considering the number and type of apology strategies used. Once more, it is observable that gender does not play an important role when using apology strategies.

Table 3. Statistical Comparison of Male and Female Respondents in Using Apology Strategies:

Researcher's Categorization

\begin{tabular}{|c|c|c|c|c|c|c|c|c|}
\hline & \multirow{2}{*}{ Strategies } & \multicolumn{2}{|c|}{ Male } & \multicolumn{2}{|c|}{ Female } & \multicolumn{2}{|c|}{ Total } & \multirow{2}{*}{$P$ value } \\
\hline & & $\mathrm{N}$ & $\%$ & $\mathrm{~N}$ & & $\mathrm{~N}$ & $\%$ & \\
\hline 1 & Compensation & 26 & 13.0 & 19 & 0.268 & 45 & 11.3 & 0.268 \\
\hline 2 & Referral compensation or reparation & 24 & 12.0 & 31 & 0.309 & 55 & 13.8 & 0.309 \\
\hline 3 & Promise of better time & 20 & 10.0 & 18 & 0.733 & 38 & 9.5 & 0.733 \\
\hline 4 & Concern for the victim & 13 & 6.5 & 25 & 0.041 & 38 & 9.5 & 0.041 \\
\hline 5 & Cursing the cause of the violation & 6 & 3.0 & 0 & 0.014 & 6 & 1.5 & 0.014 \\
\hline 6 & Expression of love & 4 & 2.0 & 2 & 0.411 & 6 & 1.5 & 0.411 \\
\hline 7 & Gratitude & 3 & 1.5 & 1 & 0.315 & 4 & 1.0 & 0.315 \\
\hline 8 & Asking victim not to be angry or worry & 2 & 1.0 & 0 & 0.156 & 2 & 0.5 & 0.156 \\
\hline 9 & Using idioms & 1 & 0.5 & 0 & 0.317 & 1 & 0.3 & 0.317 \\
\hline 10 & Invoking Allah's Name & 0 & 0 & 5 & 0.024 & 5 & 1.3 & 0.024 \\
\hline
\end{tabular}

\subsubsection{Differences in Use of Non-apology Strategies Based on Gender}

As shown in the Table 4, in general, except for the significantly more uses of "denial of responsibility", by the female respondents, there was no statistically significant difference between male and female participants in the use of other non-apology strategies.

Table 4. Statistical Comparison of Male and Female Respondents in Using Non-apology Strategies

\begin{tabular}{lcccccccc}
\hline \multirow{2}{*}{ Strategies } & \multicolumn{2}{c}{ Male } & \multicolumn{2}{c}{ Female } & \multicolumn{3}{c}{ Total } & \multirow{2}{*}{$P$ value } \\
\cline { 2 - 9 } & $\mathrm{N}$ & $\%$ & $\mathrm{~N}$ & $\%$ & $\mathrm{~N}$ & $\%$ & \\
\hline 1 & Denial of Responsibility & 3 & 1.5 & 19 & 9.5 & 22 & 5.5 & 0.000 \\
\hline 2 & Avoidance of subject or person & 2 & 1.0 & 0 & 0 & 2 & 0.5 & 0.156 \\
\hline 3 & Blame the victim & 1 & 0.5 & 3 & 1.5 & 4 & 1.0 & 0.315 \\
\hline 4 & Laughing the incident Off & 1 & 0.5 & 0 & 0 & 1 & 0.3 & 0.317 \\
\hline 5 & Brush off the incident as not important & 1 & 0.5 & 1 & 0.5 & 2 & 0.5 & 1.000 \\
\hline 6 & Offending the victim & 0 & 0 & 0 & 0 & 0 & 0 & N/A* \\
\hline
\end{tabular}




\subsection{Analysis of Research Question 4}

The last research question of the study is: what are the apology and non-apology strategies used by the Iranian ESL students that are influenced by Iranian culture and the Persian language?

\subsubsection{Effects of the Persian Culture on the Use of Strategies}

As Wierzbicka (1985) claimed, "different preferences in the use of apology forms seem to be rooted in different cultural norms and assumptions". In the Persian culture, people's feelings, face, and belongings are highly respected. Iranians are eager to have successful communication and care for keeping their close relationships. It was also pointed out that, traditionally, asking for forgiveness and apologizing was considered a face-threatening act; however, modern and educated Iranians apologize more often and consider this as a polite behaviour and the norm of a modern society.

The most frequently used IFIDs used by the participants of this study were "one expression of regret and one intensifier", which was used 143 times (35.8\%), and "one expression of regret", which was used 135 times (35.8\%). These findings prove that Iranians care very much for others and feel sorry when they unintentionally hurt the people around them. They express this regret by using intensifiers such as "very" or "really". Based on Afghari (2007), "Persian apologies are as formulaic in pragmatic structures. Two context-external variables of social distance and social dominance have a crucial effect on the frequency of apology intensifiers in various situations. The most intensified apologies are used for close friends and the least intensified are offered to strangers". Similarly, except for situation 7 , where the victim is a stranger (a university staff), the participants of the present study used the most number of intensifiers and IFIDs in situations 1,2,3,5 and 6, in which the victims are close friends, university professors or family members. However, in situation 9, which asks, "as you are carrying a chair in the lobby of the university, you hurt a fellow student's hand accidentally. What would you say?", includes the most number of IFIDs, especially an "expression of regret" with one or two intensifiers.

In another study, Shariati and Chamani (2009), stated that "apologies in Persian are formulaic and culture specific. Although Persian speakers use the same apology strategies, IFID with a request for forgiveness is used more than the others. Moreover, a combination of IFID with taking on responsibility is used in all situations".

By looking at the apology strategies, we can see that the most frequently used apology strategy was "accounts", which was used 148 times (almost 40\%) by the respondents. The next most frequently used was "an expression of selfdeficiency" which was used only 49 times. These findings show together with the most frequently used "expression of regret" show that Iranians feel sorry and express their regret when they commit an offence or hurt somebody, and they also try to give an explanation and justify the offence. The most numbers of accounts were used in situations 1, 24 , and 8 , where the victim is a close friend or the speakers university lecturer. This shows that, the participants cared very much to explain the situation and account for the offence. Denial of responsibility together with the explanation used in situations 1 and 2, highlight the fact that Iranians tend to blame other causes such as traffic jams or other excuses to express that they did not commit the violation or offence on purpose, and the cause of the violation was something out of their control. According to Afghari (2007) except promise of forbearance, which is rarely applied by Persian speakers, accounts and reparation are the most common strategies among them. Afghari's report is in line with the findings of this study as, the most frequent apology strategies used by the respondents in this study has also been accounts, compensation and reparation.

Regarding non-apology strategies, the participants did not use so many of these kinds of strategies. The total number of non-apology strategies used by respondents is only, which is very few compared to the number of apology strategies and IFIDs used. This signifies the fact Iranians care for the people they deal with, no matter what their social status or their relationship is. They regret the offences they make and they attempt to explain and compensate the violations. The use of denial of responsibility, which was the most frequently used non-apology strategy, highlights the same fact. By denying the responsibility for the violation, Iranians aim to express a third party or issue that was responsible for the offence. This denial is a kind of explanation they add to the account strategies they have used in every situation.

\subsubsection{Effects of the Persian Language on the Use of Strategies}

The findings of this study also reveal the over use of "Excuse me" by Persian native speakers. The words "excuse me" are literal translation of "bebakhshid" in Persian, which is used very frequently by Iranian ESL or EFL learners in situations where this expression is not used in the English language. In Persian the expression" bebakhshid" is used in both situations and the difference in meaning is realized from the context it is used in. That is why Iranian ESL and EFL learners tend to over use or misuse "excuse me". The following are some wrong uses of "excuse me" by the participants:

Excuse me! I had a bad cold and I wasn't able to go out. [2]

Oh, excuse me, I didn't mean to step on your

The above examples are only some of the instance that the participants of this study have wrongly used "excuse me" when they attempted to apologize or sympathize with the victims. This over use and misuse of this English expression can cause misunderstanding and can also be offensive in certain situations. The participants of this study were MESL and English literature students of the University of Malaya. These types of errors by ESL learners of such high proficiency students confirms the need for pragmatic and sociopragmatic lessons in TESOL to ensure that learners are aware of these cultural and linguistic differences across languages and cultures. According to Eslami-Rasekh and Mardani (2010), "The syllabus designers need to expose the learners to the patterns used most commonly by English 
native speakers. In this way the L2 learners avoid using repetitive use Persian apology "excuse me" which is a result of negative transfer". They have also experimented and concluded that explicit teaching of apology speech acts can improve and enhance the students' use of the speech acts of apology.

\section{Conclusion}

Since almost all the researches reviewed have been done in the EFL context of Iran, the present study aims to look at Iranian students' apology and non-apology strategies in an ESL setting (Malaysia). Looking back, Iranian participants (males and females) applied different percentages of apology and non-apology strategies. Unlike Iranian males, Iranian females employed more IFID and apology strategies to keep their successful relationships with the victim. Even if both groups used non-apology strategies in their responses, male respondents used various types of non-apology strategies to get rid of difficult situation of apologizing. Considering significance levels, the IFID strategies used by female respondents were significantly more. While, in general, except for a few strategies, there was not any significant difference between respondents considering the number and type of apology and non-apology strategies used, which means, on the whole, gender did not play a significant role. Furthermore, students' L1 and culture influenced the choice of strategies used (Afghari, 2007; Shariati and Chamani, 2009; Eslami-rasekh and Mardani, 2010).

\subsection{Limitations and Suggestions}

As mentioned before, L2 teaching should help the learners use language in social contexts and give them enough knowledge of combining utterances and communicative functions (Canal \& Swain, 1980). Bachman (1990) argued that "Learners need to know grammar, text organization rules, and the pragmatic aspects of the target language to acquire rules for proper application of linguistic forms". Unfortunately, pragmatics is usually overlooked in the L2 instruction that traditionally gives prominence to grammar and lexicon. According to Olshtain and Cohen (1981), formal instructions on the use of speech acts can accelerate the process of learning the target language. Studies reveal that apology is perceived as an intricate interaction by learners who want to re-establish the broken balance between themselves and the interlocutors. They have to realize the extent of their fault in violating social norms and provide enough support to their interlocutors. So, due to the fact that the speech act of apology plays a significant role in their communication, more extensive explorations should be done by the other scholars. The researcher's recommendations for further study are as follows:

(1) Using other instruments such as role plays, interviews, and observations in data collection.

(2) Conducting a comparative study between respondents and native speakers of English.

(3) Investigating the acceptance of apology by the victim.

(4) Finding out the most effective apology strategies that may increase the attainability of the victim's forgiveness.

(5) Pondering some supra segmental features like pitch and ton.

(6) Examining how females apologize to males or vice versa.

(7) Increasing the number of respondents.

(8) Comparing EFL and ESL learner's apology strategies.

(9) Comparing learners with different levels of English fluency.

(10) Administering this study comparing various cultures and languages.

(11) Examining pragmatic transfer among Iranian students in the ESL classroom

\section{References}

Abu Amoud, M. S. M. (2008). A study of Apology Strategies among Hebron University students. (Master dissertation, University of Malaya, Malaysia).

Afghari, A. (2007). A socio pragmatic study of apology speech act realization patterns in Persian. Speech communication, 49,177-185.

Alfattah, M. (2010). Apology strategies of Yemeni EFL university students. University of Mysore, Mysore, India.

Bataineh, R. F., \& Bataineh, R. F. (2008).A cross-cultural comparison of apologies by native speakers of American English and Jordanian Arabic. Journal of Pragmatics, 40(4), 792-821.

Cohen, A. D., \&Olshtain, E. (1985).Comparing apologies across languages. Scientific and humanistic dimensions of language, $175-83$.

Deutschmann, M. (2003). Apologising in British English (Doctoral dissertation, Umeå University).

El Samaty, M. (2005).Helping foreign language learners become pragmatically competent. Paper presented at the 10th TESOL Arabia Conference.

Eslami-Rasekh, A., \& Mardani, M. (2010).Investigating the effects of teaching apology speech act, with a focus on intensifying strategies, on pragmatic development of EFL learners: The Iranian context. Journal of Language Society and Culture, 30, 96-103.

Félix-Brasdefer, J. C. (2003). Declining an invitation: A cross-cultural study of pragmatic strategies in American 
English and Latin American Spanish.Multilingua, 22(3), 225-256.

Ghorbani, M. R. (2009). ELT in Iranian high schools in Iran, Malaysia and Japan: Reflections on how tests influence use of prescribed textbooks. Reflections on English Language Teaching, 8(2), 131-139.

Gonda, Th. (2001). The speech act of apology: Apology behavior of British English and advanced Greek speakers of English, Unpublished master's thesis, University of Essex.

Hatipoglu, C. (2003). Culture, gender and politeness: apologies in Turkish and British English (Doctoral dissertation, University of the West of England at Bristol).

İstifçi, İ. (2009). The use of apologies by EFL learners. English Language Teaching, 2(3), 15-25

Jung, E. H. S. (2004). Interlanguage pragmatics. Discourse across languages and cultures, 68, 99.

Kuhi, D., \&Jadidi, M. (2012).A study of Iranian EFL learners' understanding and production of politeness in three speech acts: Request, refusal, and apology. Theory and Practice in Language Studies, 2(12), 2624-2633.

Kwon, J. (2004). Expressing refusals in Korean and in American English. Multilingua, 23, 339-364.

Liddicoat, A.J. (2000). Everyday speech as culture: implications for language teaching. In: Liddicoat, A. J., Crozet, C (Eds.), Teaching Languages, Teaching Cultures. Applied Linguistics association of Australia, Melbourne, pp. 51-63.

Mir, M. (1992). Do we all apologize the same? An empirical study on the act of apologizing by Spanish speakers learning English. Pragmatics and Language Learning, 3, 1-19.

Munoz, V.I. (2000). A cross-cultural pragmatics study: Puerto Rican return migrant and non-migrant students' apology performance and evaluation(Unpublished $\mathrm{PhD}$ thesis, New York University).

Nagano, M. (1985). " How to Say I'm Sorry": The Use of Apologies in Japan and the United States (Doctoral dissertation, San Francisco State University.).

Nureddeen, F. (2008). Cross cultural pragmatics. Apology strategies in Sudanese Arabic. Journal of pragmatics, 40, 279-306.

Olshtain, E. (1989). Apologies across languages. In Shoshana Blum-Kulka, Juliane House \& Gabriele Kasper (Eds.), Cross-cultural pragmatics: Requests and apologies (pp. 155-173). New Jersey: Ablex.

Parsa, H. (2012). Apology strategies of Iranian ESL students.(Master's Dissertation, University of Malaya, Malaysia).

Rakowicz, A. (2009). Ambiguous Invitations: The Interlanguage Pragmatics of Polish English Language Learners. New York University.

Shahrokhi, M. (2009). A sociopragmatic study of linguistic politeness in Iranian requests and apologies.(PhD dissertation, University of Malaya).

Shardakova, M. (2005). Interlanguage Pragmatics in the Speech of American Second Language Learners of Russian: Apologies offered by Americans in Russian. (PhD dissertation, Bryn Mawr College).

Shariati, M., \& Chamani, F. (2009). Apology Strategies in Persian. Journal of Pragmatics, 42 (6), 1689-1699.

Shoja, M. (2011), Bahasa Malaysia for the University of Malaya International Students: A Needs Analysis. (Master's Dissertation, University of Malaya, Malaysia).

Taleghani-Nikazm, C. (2008). Gestures in foreign language classrooms: An empirical analysis of their organization and function. In Selected proceedings of the 2007 second language research forum (pp. 229-238).

Tamanaha, M. (2003).Interlanguage speech act realization of apologies and complaints: The performances of Japanese L2 speakers in comparison with Japanese L1 and English L1 speakers. (Doctoral dissertation, University of California, Los Angeles, California).

Thijittang, S.(2010).Pragmatics Strategies of English of Thai University Students.(PhD thesis, University of Tasmania).

Todey, E. (2011). Apology Strategies As Used by Native \& Non-Native Speakers of English.

Vollmer, H.J. \& Olshtain, E. (1989). The Language of apology in German, Cross- Cultural Pragmatics: Requests and apologies (pp. 197-218).

Walters, J. (1979). Strategies for requesting in Spanish and English: Structural similarities and pragmatic differences, Language Learning, 29 (2), 277-293.

Watts, R. J. (1989). Relevance and relational work: linguistic politeness as politic behavior. Multilingua, 8(2), 3-131.

Wee, L. (2004). 'Extreme communicative acts' and the boosting of illocutionary force. Journal of Pragmatics, 36 (12), 2161-2178.

White, R. (1993). Saying please: Pragmalinguistic failure in English interaction. ELT Journal, 47 (3), 193-202.

Wildner-Bassett, M. E. (1984). Improving pragmatic aspects of learners' interlanguage: A comparison of methodological approaches for teaching gambits to advanced adult learners of English in industry. G. Narr.

Wierzbicka, A. (1991). Cross-cultural pragmatics: The semantics of human interaction. New York: Mouton de Gruyter.

Wierzbicka, A. (1985). Different cultures, different languages, different speech acts. Journal of Pragmatics, 9, 145-178. 
Wolfson, N., Marmor, T., \& Jones, S. (1989). Problems in the comparison of speech acts across cultures. Cross-cultural pragmatics: Requests and apologies, 174-196.

Wolfson, N. (1989). Perspectives: Sociolinguistics and TESOL. New York: Newbury House.

Wouk, F. (2006).The language of apologizing in Lombok, Indonesia. Journal of Pragmatics, 38 (9), 1457-1486.

Farashaiyan, A., \& Amirkhiz, S. (2011). A Descriptive-Comparative Analysis of Apology Strategies: The case of Iranian EFL and Malaysian ESL University Students. English Language Teaching, 4(1), p224.

Yeganeh, M. T. Apology Strategies of Iranian Kurdish-Persian Bilinguals: a Study of Speech Acts Regarding Gender and Education.

Yule, G. (1996). Pragmatics.

Zimin, S. (1981). Sex and politeness: Factors in first and second-language use. International Journal of the Sociology of Language, 27, 35-58. 